\title{
Assessment of Educational Quality and Associated Factors: The Case of Arba Minch College of Health Sciences in 2017, South Ethiopia
}

\author{
Girma Gilano (iD) and Samuel Hailegebreal \\ Department of Health Informatics, Arba Minch University College of Health Science Nech Sar Campus, P.O. Box 21, \\ Arba Minch, South West Ethiopia \\ Correspondence should be addressed to Girma Gilano; gilanog@yahoo.com
}

Received 2 June 2020; Revised 5 November 2020; Accepted 27 February 2021; Published 20 March 2021

Academic Editor: Gwo-Jen Hwang

Copyright (C) 2021 Girma Gilano and Samuel Hailegebreal. This is an open access article distributed under the Creative Commons Attribution License, which permits unrestricted use, distribution, and reproduction in any medium, provided the original work is properly cited.

\begin{abstract}
Introduction. Over the decades, improving the quality of education has been pronounced frequently in many studies. It became a political argument in different media across the globe and the theme of courtesy among scientists. The concern about education is not something you ignore or consider later, so the attempts to improve are increasing with the quality matter going longer and continuing to date. Thus, the primary aim of this work was to assess the quality of education and its associated factors for the future improvement in the study site. Methods. An institution-based cross-sectional study was conducted in Arba Minch College of Health Sciences (AMCHS) students and staff from all departments. Ethical clearance was received and verbal consent was secured beforehand. After processing, data was entered into Epi Info and then transferred and analyzed in SPSS 25.0. Result and Discussion. The overall quality of education in the college was $2.87 \pm 1.12$. Administrative services, reading places, and resources took a larger share of poor quality. Accessibility, friendliness of staffs to each other and students, availability of clear guideline of conduct, presence of effective, accurate, and promotive services, high standard administrative buildings, availability of standard catering service, availability of standard laboratories, communication, and exchanges with similar level colleges in the region, weekly time table, weekly load, distance, etc. and some sociodemographic factors were associated with poor quality of education. Thus, the college inquired to welcome the aforementioned shortcomings improvement and to provide enough solutions.
\end{abstract}

\section{Introduction}

Over the years, improving the quality of education has been pronounced frequently in different studies. It becomes a political argument on media as the need for improvement of quality in education eagerly grows [1]. While the number of learners and teaching institutions is highly increasing, the quality of education started to become a concern of every higher education institution [2]. In different countries, they have controlled the quality of higher education in various ways. Berit's peer review model is one way by which national quality assurance agencies control how higher education institutions work and perform. But as much as the role of producing a productive next generation is the first work of higher education, the quality of education becomes a riddle to the academia itself and other stakeholders from the outside [3]. Some studies focused on the measurement of students' achievement considering it should coincide with the curriculum objectives and context of learning especially when collecting data. Overall, quality has been the problem of all higher education institutions and needs critical assessments [4]. There were many curricula to succeed with need for medical students to help patients, though not all led to general recognition in the acquisition of knowledge and change of necessary behaviors [5]. Particularly in health, we can improve the quality of education through outcomebased education among which continuous quality improvement, constructive alignment, presentation of outcome and assessment, and evaluation tools were main [6]. A framework synthesized from the literature by Ogrinc and 
coworkers in 2003 surely pronounced that schooling the knowledge and skills of practice-based learning and improvement to medical students and residents is necessary and is an important foundation for improving patient care [7]. They also found online learning and materials much helpful in improving students' knowledge in other pieces of literature [8]. However, unlike educational colleges, health teaching colleges in Ethiopia and probably in most of the sub-Saharan African countries were not the focus of educational quality assessments, although many NGOs and stakeholders were implementing different mechanisms in search of quality education that would provide the muchrequired good child and maternal care recently. From this, we understood that there were a variety of ways to improve the quality of education especially in health colleges in Ethiopia where such information was too limited. Thus, assessing the quality of Arba Minch College of Health Sciences education quality is very vital for improving the provision of quality of care through its graduates. Finding out associated factors that stakeholders would be thriving to improve through implementing provided solutions by this assessment.

\section{Literature Review}

Over time, governments increasingly started resorting to standardized tests as indicators of the quality of education and the quality of teaching even though inadequacies with such tests went the other way. However, evaluation of the quality of education must not solely test scores since a range of factors is out there [9]. It assumes the quality of education depends on students' attendance and socioeconomic composition from some studies [10]. Other studies showed quality in education depends on the differences among instructors about implementation-specific strategies [11]. Language proficiency, resistance to active learning, absenteeism, lack of interest to learn, poor communication, etc. were reported to affect the quality of education by $32 \%$. Negative behaviors and attributes of the low level of qualifications, availability of resources, extensive use of part-time teaching, dedication, skill, pedagogy, cooperation, moonlighting, etc. were factors considered to be vastly affecting the quality of education [12]. Students were also highly complaining about the services provided in universities such as a cafeteria, dormitory, a student clinic, guidance, and counseling and it requires the office to develop the capacity of counselors, nurses, laboratory technicians, pharmacists, and cafeteria workers [13]. But some studies summarized quality education, as we cannot achieve it through just quality parameters and need a model that accompanies most quality entities of higher education [2]. Most of the influencing factors from kinds of literature were summarized as curriculum-related, staff-related, e-service-related, career perspective-related, infrastructure-related library-related, administrative service-related, and those related to the location of institutions providing the service.

Due to the current influence of globalization and the speeding up of information generation, there is a significant change in curriculum and academic structure. The due issue needs a more flexible curriculum and other variables that fit the dynamism of the current world [14]. Almost every fact and ideology in an education-based curriculum needs an overall transformation for higher quality achievements in higher education. But it is very common to see students threatened with their career perspective while positive expectations increase motivation and engagement, though has an unquestionable effect on the quality of education [10]. Critical consideration of safety in the school environment for staff and students plays a paramount dividend in keeping the education quality. When all attention cannot go for education but also security and safety, it drastically affects the quality of education [15]. Continuous observation of the educational environment was necessary. Globalization by itself has not affected the change of curriculum; however, it came with bullying, violence, and other privacy and confidentiality problems in schools. We expect an educational place where these things are prevented, and those who had conflict resolution curricula in place to have a positive influence on quality education [16]. The educational place with full facility supporting learning library in the literature showed a rise in educational quality. They found the library service which is not brought by trained personals to be a problem causing and undoubtedly affecting the educational quality of service [17]. In 1995, Harvey uncovered that the service being provided in schools depends on resources such as qualified staff, adequately stocked libraries, well-equipped laboratories, and students with satisfactory qualifications at the entry to the school. From these points outshone by Harvey, we draw a lot that can help today to raise respective educational quality [18]. But an alternative explanation was necessary for a study conducted by Tesfaye Chala in Nekemte Teachers College that showed infrastructure did not show any difference. Of course, there could be different narration for how it is not affected by the quality of education. Indeed, the quality of education could be more dependent on due professionals taking part in the field contributing to learning and teaching rather than raw materials [17]. Another surprise from the same study was the involvement of administrative staff in education that would prompt improvement. The reason for that idea was academic administrators and faculty members who took the responsibility for setting up goals for the teaching-learning process; developing and offering academic courses and programs would be prompting. Here it was believed that we might need important changes in how the interaction of academic administrators and faculty members with learning for the improvement of quality education worked [19]. It warns quality of medical education measured through the impact of educational and procedural quality improvement in terms of knowledge, behavioral change, and patient care [20]. One critical study by David Frisvold and Ezra Golberstein showed that improving school quality, peopleteacher ratio, average teachers' wage, and length of the school year had a positive influence on later life [21].

In the literature, there were a few studies in the country concerned about the quality of education especially in midlevel higher education health colleges like Arba Minch College of Health Sciences, although over 70\% [22] of health 
services in Ethiopia depend on trainees from these midlevel health colleges. Few of the existing studies in the country were focusing on the assessment system, materials, and other teachers or student-focused areas $[9,13,17,22]$. Thus, the current study applied to different variable categories from a variety of higher education quality assessment models and assessed the Arba Minch College of Health Sciences. Indeed, it was mainly aimed at determining the quality of education of Arba Minch College of Health Sciences and identifying factors affecting its educational quality for better care provision as a result of the outstanding quality of education.

\section{Methods and Materials}

An institution-based cross-sectional study was conducted in Arba Minch College of Health Sciences (AMCHS) in the South Nation Nationalities and Peoples Regional (SNNPR) state of Ethiopia on the sample drawn from all students and staff from November 2017 to August 2017. AMCHS is among the four health science colleges in southern Ethiopia. The study included all eligible students who were nonrepeated, not under the disciplinary situation, and at least two years since admission to the college, and staff (instructors and administrative staffs) who worked for two years and could take part in the study. AMCHS has clinical nursing, midwives, health extension, health information technology, pharmacy, laboratory technicians, and anesthesia departments. The college has been actively taking part in research works since its establishment. We collected data using the tool from previous studies to assess the quality of education $[1,2,4,23,24]$.

We here define the quality of education as fitting to the purpose. The eight criteria used to measure educational quality were curriculum, workers, electronic services, library, administrative service, location, career, and resources. They were adapted from the higher education quality assessment literature $[1-4,19,23,25]$. The criteria used to assess were five-point Likert scale questions; we decided the score of eight to be quality education (the best) and we considered the score of zero the worst. We dichotomized the score as $\geq 3.5$ (good educational quality) and all else poor educational quality. We assumed the stratified sampling technique for there was year two, year three, and staff members of different units in groups. The tool comprising general educational quality-related questions included "staffs engagement in research activity," "good professional experience to teach and share knowledge," "the college is cooperative," "availability of appropriate academic advising," "availability of transportation services (to and out of college)," "accessibility of college for the community," "availability of safety and security department," "sufficient working for enough hours," "friendliness of staff to each other and students," "clear exam guideline and advice to follow," "effective, accurate, and prompt service," "the college is cooperative in all aspects," "modern and higher quality laboratories/demonstration," "good perspectives for professional career or development," "availability of e-service through social networks," "availability of textbooks and journals for students and instructors," "easy borrowing process in the library," "sufficient place of sitting and reading in the library," "availability of sports facilities," "availability of medical facilities," "high-quality good administration buildings," availability of service to host social and cultural events," "the college website provides academic and administrative services," "standard catering service," and "availability of communication skill throughout the college". We measured these through "yes/no." Sociodemographic variables (sex, age, education, marriage, monthly income, distance from college, ethnicity, department/profession, and weekly load) were measured through different corresponding standard measurements. Age, monthly income and distance from residence to college, academic year (or years in college), and weekly load were measured on continuous parameters, while all other sociodemographic variables were measured using a categorical scale. Then, considering each department or unit as a stratum, $10 \%$ of each class year students except for the first year, instructors, and other administrative (management) staff were included in the study. Sociodemographic variables were assessed separately for staff and students and then combined while general quality-related questions were employed similarly for both. Proportional allocation to size method was applied to get the required sample. It took this sampling method after overwhelming works of literature and identification of the recommendations [13]. A total sample of 200 individuals were obtained, such that 100 2nd-year, 85 3rd-year students, 15 instructors, and administrative staff were drawn. We asked each of the selected participants to contribute. Thus, securing the written consent of participation, there were 194 participants who availed and gave their responses.

The tool for capturing data was prepared in English and then translated into the Amharic language to make it appropriate for its understandability. The Amharic version again was translated back to English to check the consistency of meaning by language instructors. The internal consistency for the questionnaire was checked and Cronbach's alpha was 0.736 which was very good.

It involved trained data collectors and experienced master qualified supervisors with the pretest tool and data collection. They checked the data and submitted it to the investigator. Epi Info 7 for entry and SPSS 25 for analyses were used. Statistical analysis was used to identify variables associated with the quality of education in SPSS. The association of quality of education with sociodemographic and other variables was also checked using binary logistic regression. We got ethical clearance from AMCHS (Arba Minch College of Health Sciences) research and publication core process owner office and board of an ethical committee of the college. A structured self-administer questionnaire was finally used for data collection from 185 students and 15 staff/instructors after written consent was collected from each individual taking part.

\section{Results}

Of the 200 students learning in Arba Minch College of Health Sciences and instructors engaged in teaching in the college, 194 (97\%) agreed to take part. The sociodemographic characteristics of the study population are shown in 
Table 1 . Approximately 115 (59\%) of the participants were female and $41 \%$ were male. Over three-fourths of the participants were 23 years old or younger and only less than $11 \%$ were 25 years old or older. The most common participants were from the south nation nationality people region (SNNPR) (69\%), followed by Oromo (17\%), and least commonly Amhara $10.8 \%$ in their ethnic group category. Two-thirds of the participants were single (66.5\%) and onethird $(33 \%)$ of them were married with the remaining either separated or divorced. More than half of those taking part (54.1\%) were from health extension (HEX), clinical (CN), or midwife departments (MW) while the remaining half were from four other departments. In most of the departments, $82.5 \%$ of the participants learned/worked at least 34 hours per week while half of the participants were in the college for least for 2 years and three-fourths of the participants needed to walk 1 kilometer to the college (Table 2).

The average distance every student or staff had to move or walk to college was $1.31 \pm 0.593$ and the mean age of the participants was $21.96 \pm 2.085$. The weekly load for each department was $32.4 \pm 5$ while the monthly income of participants was $964.3 \pm 2400$. The variation of income is very high in staff salaries, but on checking for the outlier, it has less effect.

4.1. Quality of AMCHS Education. Table 2 shows the degree to which respondents agree that the colleges have a quality education. We calculated the mean and the standard deviation of the scores of the eight items used to measure the educational quality of the college for each item. The items with the biggest levels of quality were those with the largest mean scores. These were career opportunity (3.24 \pm 1.15$)$, curriculum (3.18 \pm 1.16$)$, location ( $3.14 \pm 1.107)$, and staff equipping students sufficiently $(3.00 \pm 1.13)$. The staff members and students were most describing low education quality in administration services $(2.58 \pm 1.22)$, library services $(2.31 \pm 1.11)$, e-service $(2.56 \pm 1.06)$, and resources $(2.97 \pm 1.04)$ (Table 2). Most respondents (64\%) reported that the curriculum provides appropriate topics for the existing market. More than half (52\%) of the respondents were serious about how the administrative service of college is going; however, the library service could not win the interest with $46 \%$ only reporting quality service (Figure 1 ).

Around half $(51 \%)$ of respondents reported good e-services in the college while similarly $60 \%$ of the respondents were positive about the infrastructure in the college. More than half (65\%) reported there is a wonderful opportunity for a career after college. The percentage of educational quality for the parameters was all below the cutpoint of $70 \%$.

The overall quality of education as rated by the respondents was $2.87 \pm 1.12$. This is not strange as Table 2 shows most of the criteria were rated below the operational definition of quality.

4.2. Statistical Analysis of Associated Factors. Table 3 shows the relationship between each factor and educational quality. Department, weekly load, distance, and level of education
TABLE 1: The sociodemographic characteristics of respondents.

\begin{tabular}{lc}
\hline Variables & $N(\%)$ \\
\hline Sex & - \\
Male & $79(40.7)$ \\
Female & $115(59.3)$ \\
Age in years & - \\
$\leq 20$ & $52(26.8)$ \\
21 & $44(22.7)$ \\
22 & $29(14.9)$ \\
23 & $28(14.4)$ \\
224 & $41(21.1)$ \\
Education & - \\
Student & $178(91.8)$ \\
B.Sc. & $6(3.1)$ \\
Master's degree and above & $10(5.2)$ \\
Marital status & - \\
Single & $129(66.5)$ \\
Married & $65(35.5)$ \\
Residence & - \\
Rural & $129(66.5)$ \\
Urban & $65(33.5)$ \\
Ethnicity & - \\
SNNPR & $134(69.1)$ \\
Amhara & $21(10.8)$ \\
Oromo & $33(17)$ \\
Others & $6(3.1)$ \\
Department/unit & - \\
HEX & $26(13.4)$ \\
CN & $45(23.2)$ \\
MW & $34(17.5)$ \\
HIT & $27(13.4)$ \\
LAB & $24(12.4)$ \\
PHAR & $26(13.4)$ \\
Others & $12(6.2)$ \\
\hline
\end{tabular}

were significantly associated with the quality of education. The remaining sociodemographic variables such as academic year or experience, monthly income, gender, age, original residence, marital status, and ethnicity did not have a significant influence on the quality of education. Other factors included accessibility, friendly services, availability of clear guideline of conduct in the college, presence of effective, accurate, and promotive services, high standard administrative buildings, availability of standard catering service, availability of standard laboratories demonstration rooms for learning, engagement of college communication and exchanges with similar level colleges in the region, weekly time table, weekly load, distance from the college, and the program providing enough elective topics and having a significant association with quality of education.

Quality of education was less likely affected by distance from residences to college ( $\mathrm{OR}=0.151,95 \% \mathrm{CI} 0.42$ to 0.540 , $p<0.01)$. Presence of elective topics in the program was 9.6 times more likely associated with the quality of education $(\mathrm{OR}=9.6,95 \% \mathrm{CI} 2.178$ to $42.463, p<0.001)$ and similarly engagement in communication and exchanges with similar level colleges in the region was 5 times more likely associated with educational quality ( $\mathrm{OR}=4.5,95 \%$ CI 1.042 to 19.43 , $p<0.05)$. The weekly timetable was less likely to affect the educational quality $(\mathrm{OR}=0.046,95 \% \mathrm{CI} 0.0 .009$ to 0.236 , 
TABLE 2: The descriptive statistics of the quality of education of AMCHS in 2017.

\begin{tabular}{lccc}
\hline Variables & Mean & Std. deviation & Educational quality \\
\hline (1) Curriculum & 3.18 & 1.17 & Poor quality \\
(2) Staff equipping students sufficiently & 3.00 & 1.13 & Poor quality \\
(3) Administration & 2.59 & 1.22 & Poor quality \\
(4) Reading places & 2.31 & 1.11 & Poor quality \\
(5) Electronic service & 2.56 & 1.06 & Poor quality \\
(6) Resources & 2.98 & 1.04 & Poor quality \\
(7) Location & 3.14 & 1.07 & Poor quality \\
(8) Career & 3.24 & 1.15 & Poor quality \\
Average & 2.87 & 1.12 & Poor quality \\
\hline
\end{tabular}

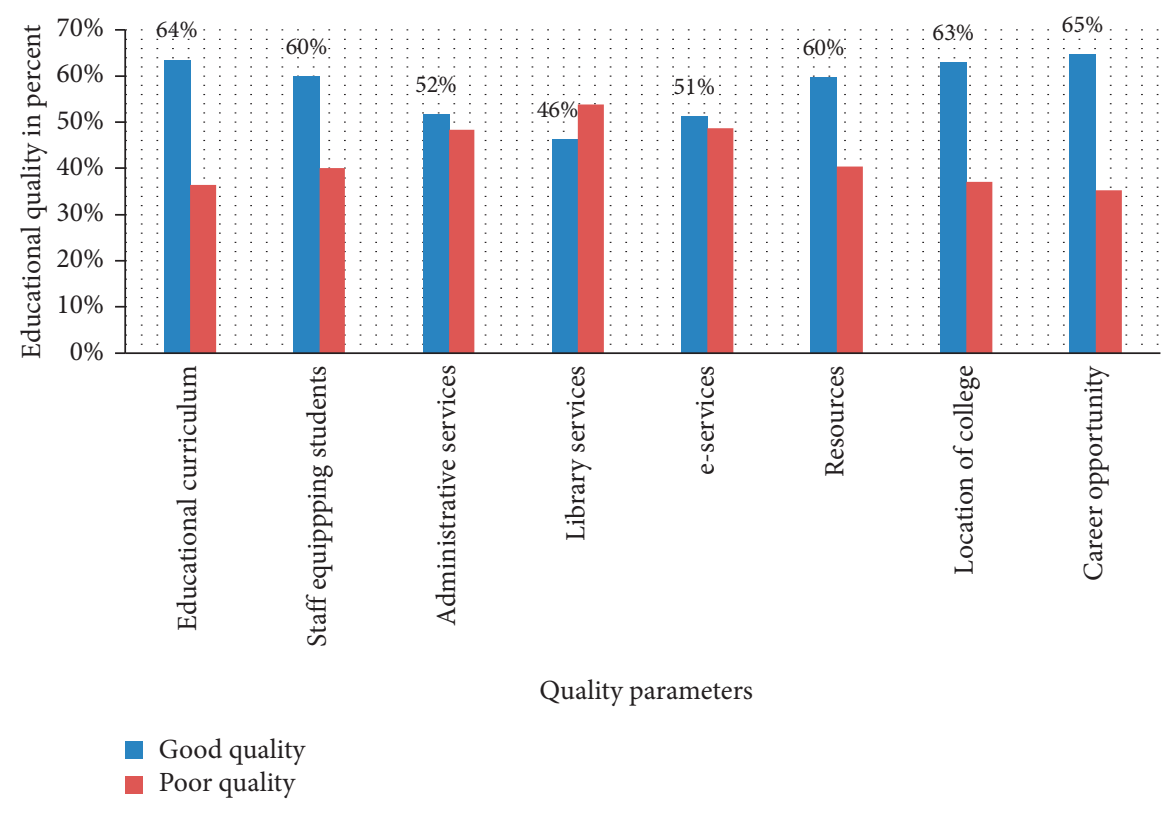

Figure 1: Distribution of educational quality per parameter in Arba Minch College of Health Sciences.

TABLE 3: Distribution of factors associated with the educational quality AMCHS in 2017.

\begin{tabular}{|c|c|c|c|c|c|}
\hline S. no & Variable & $p$ value & OR & Lower 95\% & Upper $95 \%$ \\
\hline \multirow{4}{*}{1} & Student & - & - & - & - \\
\hline & B.Sc. & 0.027 & 78.8 & 1.65 & 3755 \\
\hline & Master's degree and above & 0.249 & 13.3 & 0.0163 & 1089 \\
\hline & $\mathrm{CN}$ & - & - & - & - \\
\hline \multirow{6}{*}{2} & PHEX & 0.001 & 55.200 & 12.773 & 24130 \\
\hline & MW & 0.002 & 121.310 & 5.556 & 2649 \\
\hline & HIT & 0.015 & 32.945 & 1.987 & 546.334 \\
\hline & MLT & 0.002 & 176.437 & 6.46 & 4819 \\
\hline & PHARM & 0.002 & 146.501 & 6.258 & 3429 \\
\hline & Others & .106 & 10.378 & .062 & 177.039 \\
\hline 3 & Distance from home to college & 0.004 & .151 & .042 & .540 \\
\hline 4 & Weekly load & 0.007 & 9.617 & 2.178 & 42.463 \\
\hline 5 & Original residence & 0.069 & 0.263 & 0.062 & 1.110 \\
\hline 6 & The program provides enough elective topics & 0.003 & 9.617 & 2.178 & 42.463 \\
\hline 7 & Weekly time table & 0.000 & 0.046 & 0.009 & 0.236 \\
\hline 8 & Communication skill & 0.072 & 110.746 & 0.657 & 18660 \\
\hline 9 & Exchange with other colleges & 0.044 & 4.50 & 1.042 & 19.430 \\
\hline 10 & Quality of lab & 0.034 & 0.231 & 0.060 & 0.896 \\
\hline 11 & Standard catering & .020 & 0.010 & 0.000 & 0.490 \\
\hline 12 & High standard admin building & 0.002 & 0.003 & 0.000 & 0.117 \\
\hline 13 & Effective, accurate, and promotive services & 0.012 & 24.291 & 2.044 & 288.661 \\
\hline 14 & Clear guidelines & 0.007 & 9.264 & 1.829 & 46.932 \\
\hline 15 & Friendly services & 0.025 & 4.950 & 1.228 & 19.958 \\
\hline 16 & Accessibility of the college & 0.020 & 8.3770 & 1.396 & 50.256 \\
\hline
\end{tabular}

Note that the full-length name of every variable in all tables and figures was described in the variable lists. 
$p<0.001)$ while the weekly load of each department was 10 times more likely to affect the educational quality in the college $(\mathrm{OR}=9.6,95 \% \mathrm{CI} 2.178$ to $42.463, p=0.007)$. The availability of standard laboratories demonstration rooms for learning was less likely to influence the quality of the education $(\mathrm{OR}=0.231,95 \% \mathrm{CI} 0.060$ to $0.896, p<0.05)$ and in the same way availability of high standard administrative buildings was less likely associated with quality of education $(\mathrm{OR}=0.01,95 \%$ CI 0.0 to $0.49, p<0.01)$. Effective, accurate, and prompt services were 24 times more likely to affect educational quality in Arba Minch College of Health Sciences $(\mathrm{OR}=24,95 \%$ CI 2 to $288, p<0.05)$, and availability of clear guidelines of conduct in the college was 9 times more like $(\mathrm{OR}=9,95 \% \mathrm{CI} 1.8$ to $46.9, p<0.01)$. The friendliness of the staff to each other and students was also 5 times more likely associated with the quality of education (OR $=5,95 \%$ CI 1.23 to $219.9, p<0.05)$. Accessibility of the college was 8 times more likely associated with education quality $(\mathrm{OR}=8.4,95 \%$ CI 1,4 to $50.2, p<0.05)$. The binary logistic regression model in Table 3 had a goodness-of-fit under the Hosmer-Lemeshow test $\left(\chi^{2}=8.265, p=0.408\right)$. It had the Cox-Snell R2 and Nagelkerke R2 of 0.491 and 0.729, respectively (Table 3 ).

\section{Discussion and Implication}

The mean score of the overall attitude of educational quality among staff and students in Arba Minch College of Health Sciences was $2.87 \pm 1.12$ measured by a five-point Likert scale. The overall way people think of the quality of education was less below the average score of 3.5 in college (Table 2). Among the items measured of educational quality, we found reading places or libraries associated with the highest levels of poor quality, while the item associated with the highest level of quality was career. These are consistent with the study conducted elsewhere showing $84.3 \%$ of students' satisfaction in education explained by library service quality revealing there is a significant correlation between educational quality and library-related services [26]. Career prospects proved to have a long-term effect on education-related qualities $[27,28]$. The curriculum in the current study was described by a significant number of participants (64\%) as a quality for it provides enough elective topics to select from. Other studies showed that authorities of higher education institutions should design their curriculum as if academic success can reflect the higher odds to get success in post-study professional life [29]. Around half (52\%) of the respondents have reported there was a quality of administrative services. This agrees with the study conducted in China which explained management and administrative services have a paramount impact on the quality of education [30]. Only 51\% of participants evaluated electronic services in a good range. But a study conducted in Greece was consistent with the current finding showing that electronic service creates a problem for students that showed the difference in the level of interest to learn through e-services and being tired of these services (Figure 1) [31].

Under sociodemographic data, only a few variables had significant associations with the quality of education. Factors like income and education worth nothing to include in the analysis as there was a large number of student participants than staff and the salary of staff was larger than that of students. Other factors such as age, sex, residence, and ethnicity had no association with educational quality. However keeping other factors constant and taking "others" as a reference, being in clinical, health extension (public health department), midwifery, health information technology, and medical laboratory departments showed a strong correlation with the quality of education. Studies carried out on similar issues revealed departments had a prime influence on teachers' loyalty which led to the poor quality of education [32]. The distance each participant has traveled to college was inversely associated with the quality of the education. Other studies discussed that distance and educational quality were inseparable two combined things that are supportive [33]. The absence of dormitories and nearby rent houses might have caused the problem for the current study participants. The weekly load was an independent predictor of the quality of education. And this finding is consistent with a study in Iran that showed the weekly load was highly affecting the quality of education [34]. Participants who have B.Sc. degrees were more likely to report the quality of education. This caused a concern related to the ability to know good and poor quality among participants (Table 3 ).

The sufficiency of the curriculum was one factor that was acknowledged by participants. Studies in other areas had shown that curriculums with enough elective topics had enough impact on students and contributed to the quality of education [27, 34]. Similarly, the exchange of the college with other colleges is vital by participants. This might show the impossibility of modern schools to stand alone where it matters. In comparison with other studies, promoting local and across the nation exchange and the dissemination of successful education policies and strategies, building on existing national and regional communication and knowledge platforms was found to be very crucial for the quality of education $[19,25]$. High standard laboratories or demonstration rooms, high standard catering, and high standard administrative buildings were also inversely correlated to the quality of the education. Other studies described the demonstration as a crucial and the only way to gain the skill to ensure educational quality [35]. The importance of having standard practical teaching rooms, catering, and quality buildings was also explained elsewhere [36]. This might be because of the positive values these variables have in determining the quality of education for the participants. Effective, accurate, and prompt services, clear guidelines, friendly services, and accessibility of the college have a clear association with the quality of the education. Studies elsewhere described that, without clearly stated guidelines, it has forced schools to make difficult last-minute decisions on whether to cancel classes, remain open, or change school events, and so on [37]. Guidelines were also explained as basic instruments to keep schools or colleges standing steady where the friendliness of the staff to each other and students in other studies was described as the golden service especially for adolescents and can protect students from many 
dangers in ages [38]. It was also explained that schools need to provide prompt services, demonstrate a willingness to help, and respond to student inquiries as much as possible [39]. In the same way, accessibility is an economic concern, especially for students. Traveling cost, payment for internal services, and others which were in the conclusion of the current study were the encounters associated with accessibility [39].

\section{Conclusion}

We found the educational quality of Arba Minch College of Health Sciences poor. The overall perception of educational quality on a one-to-five scale was $2.87 \pm 1.12$. Nearly four of the eight parameters used to measure the quality of the education scored well, but they all scored below the requirements. However, equally half of the parameters have recorded a score of $\leq 3$. Thus, the overall quality of education completely remained below the average once again. Other factors including accessibility of the college, friendliness of staff to each other and students, availability of clear guideline of conduct in the college, presence of effective, accurate, and prompt services, high standard administrative buildings, availability of standard catering service, availability of standard laboratories demonstration rooms for learning, engagement of college communication and exchanges with similar level colleges in the region, weekly time table, weekly load, distance, the program providing enough elective topics, weekly load, and distance from the college had significant association with educational quality of the college and need clear attention.

\section{Limitation}

The tool that we used for the assessment was a standard tool applied in many countries; however, the difference of places might affect the results. We took Arba Minch College of Health Sciences conveniently, so the findings are limited to the college. The mixing of students and staff members has shown some difficulties, especially when considering monthly income as a variable. Therefore, precautious usage is recommended.

\section{Future Scope}

There has been extended talk regarding the quality of higher educations for many years; however, there was no assessment in health colleges that ever identified and showed gaps for the actions to be focused on. As per the findings of the current study, we recommend the following measures. Allowing fair and appropriate department selection, curriculum with much more elective topics to select from, an increase of communication among institutions of the same level, clear guidelines for every service in the college including exam, and friendliness services of staff to each other and students must be attained. Transportation access to college and absence of electricity during the night time need consideration. Furthermore, health teaching institutions was supported with continuous assessment of the quality of education rather than the mere implementation of different criteria set by various national and international aid organizations, since the real gaps persisted in the presence of those actions [40, 41].

\section{Data Availability}

All data generated or analyzed during this study are available from the corresponding author on a reasonable request.

\section{Ethical Approval}

The authors conducted the study after the Arba Minch College of Health Sciences ethical review board reviewed the protocol. They obtained ethical clearance for this purpose. Participants were well informed to continue in the study or decline. All information related to voluntary participation, refusal and withdrawal, privacy, benefits, and compensation of participation, risks of participation, procedures, and the purpose of the study was explained and clarified.

\section{Consent}

Only participants who agreed and signed the participation consent were interviewed. The authors collected nonparticipant identifying data from students and staff. Data collectors, supervisors, and principal investigators were able to access the collected data. The authors kept the data secure to prevent exposure.

\section{Conflicts of Interest}

The authors declare that the study was conducted in the absence of any commercial or financial relationships that might be potential conflicts of interest.

\section{Authors' Contributions}

GG was responsible for proposal development, analysis, report writing, and conception of the title, and $\mathrm{SH}$ was responsible for data entry, drafting, and editing the manuscript.

\section{Acknowledgments}

The authors received a fund for this study from the Arba Minch College of Health Sciences office of research publication core process owner. The authors acknowledge Arba Minch College of Health Sciences for guaranteeing every necessary funding for the study. They are also grateful to all who were involved directly or indirectly in the provision.

\section{Supplementary Materials}

The questionnaire used to capture data (instrument) was included and available for use. (Supplementary Materials)

\section{References}

[1] T. kellaghan and V. Greaney, Using Assessment to Improve the Quality Education, UNESCO International Institute for 
Educational Planning, Paris, France, 2001, http://www. unesco.org/iiep.

[2] Y. A. Noaman, M. A. H. Ragab, G. A. Fayoumi, M. A. Khedra, and I. A. Madbouly, "HEQAM: a developed higher education quality assessment model," in Proceedings of the 2013 Federated Conference on Computer Science and Information Systems, pp. 739-746, Kraków, Poland, September 2013.

[3] G. H. Aas, B. Askling, K. Dittrich et al., Assessing Educational Quality: Knowledge Production and the Role of Experts, European Association for Quality Assurance in Higher Education (ENQA), Etterbeek, Belgium, 2009, http://www. enqa.eu/pubs.lasso.

[4] The Latin-American Laboratory for Assessment of the Quality of Education, Measuring and Comparing Educational Quality in Latin America, UNESCO International Institute for Educational Planning, Paris, France, 2013.

[5] P.-J. Roshini, S. Vanessa, R. Gillian et al., "The state of quality improvement teaching in medical schools: a systematic review," Journal of Surgical Education, vol. 77, no. 4, pp. 889-904, 2020.

[6] 15 ways to improve education quality with outcome-based education, https://www.creatrixcampus.com/blog/15-ways-toimprove-education-quality-and-student-achievement-with-out come-based-education.

[7] G. Ogrinc, L. A. Headrick, S. Mutha, M. T. Coleman, J. O’Donnell, and P. V. Miles, "A framework for teaching medical students and residents about practice-based learning and improvement, synthesized from a literature review," Academic Medicine, vol. 78, no. 7, pp. 748-756, 2003.

[8] W. Hanushek, L. B. Resnick, D. P. Resnick, and C. Guilfoyle, Evaluation and Assessment of Students, Teachers and Education, United Educators, Bethesda, MD, USA, 2007, http:// www.unite4education.org.

[9] A. G. Gemechu, "Assessing factors affecting the implementation of continuous assessment in rift valley university college with special attention to technical and vocational educational training (TVET) programs at adama main campus, east shoa, oromia regional state, Ethiopia, east africa," Middle Eastern \& African Journal of Educational Research, vol. 7, p. 74, 2014.

[10] J. W. Luyten, J. Scheerens, A. J. Visscher, R. Maslowski, B. Witziers, and R. Steen, "School factors related to quality and equity. Results from PISA 2000. OECD,” 2005, https://research. utwente.nl/en/publications/school-factors-related-to-quality-andequity-results-from-pisa-2000.

[11] A. Yirdaw, "Quality of Education in Private Higher Institutions in Ethiopia: The Role of Governance," $S A G E$, vol. 6, no. 1, 2016.

[12] T. Regassa, T. Tolemariam, B. Ferede, A. B. Hunde, and A. Lemma4, "Quality of education: the case of Jimma University," Education, vol. 3, no. 5, pp. 267-278, 2013.

[13] C. Chung, "“Changing engineering curriculum in the globalised world", new horizons in education. Hong Kong," ERIC, vol. 59, no. 3, pp. 59-70, 2011.

[14] S. L. Harris and S. Lowery, "A view from the classroom," Educational Leadership, vol. 59, no. 8, pp. 64-65, 2002.

[15] R. L. Peterson and R. Skiba, "Creating school climates that prevent school violence," The Clearing House: A Journal of Educational Strategies, Issues and Ideas, vol. 74, no. 3, pp. 155-163, 2001.

[16] T. Chala, "Inputs and process factors affecting the quality of training in Nekemte college of teachers education, Ethiopia," Science, Technology and Arts Research Journal, vol. 3, no. 3, pp. 166-175, 2014.
[17] L. Harvey, "Editorial," Quality in Education, vol. 1, no. 1, pp. 5-12, 1994.

[18] Board Responsibility for the Oversight of Educational Quality: Association of Governing Boards of Universities and Colleges, AGB statement, 2011.

[19] C. R. Meyer, "Good practice," Minnesota Medicine, vol. 95, no. 4, p. 4, 2012.

[20] T. Hasan, "Doctors or technicians: assessing quality of medical education," Advances in Medical Education and Practice, vol. 1, pp. 25-29, 2010.

[21] D. Frisvold and E. Golberstein, "School quality and the education-health relationship: evidence from blacks in segregated schools," Journal of Health Economics, vol. 30, no. 6, pp. 1232-1245, 2011.

[22] World Health Organization, Mid-level health providers a promising resource to achieve the health Millennium Development Goals: Global Health Workforce Alliance, Report. WHO, Geneva, Switzerland, 2010, https://www.who.int/ workforcealliance/knowledge/resources/Final_MLP_web_2.pdf.

[23] D. C. Bennett, Assessing Quality in Higher Education, Association of American Colleges \& Universities, Washington, D.C., USA, 2001, https://www.aacu.org/publicationsresearch/periodicals/assessing-quality-higher-education.

[24] UNESCO, "Education in an interconnected world: ensuring inclusive and equitable development," Global Education Meet, 2018, https://en.unesco.org/covid19/educationresponse/ solutions.

[25] L. Atinkut and Y. Abe, "Impact of library service quality on students' satisfaction in higher educational environments: the case of wollo university," Asian Journal of Economics, Business and Accounting, pp. 1-6, 2019.

[26] S. M. Dougherty, "The effect of career and technical education on human capital accumulation: causal evidence from Massachusetts," Education Finance and Policy, vol. 13, no. 2, pp. 119-148, 2018.

[27] OECD, Equity and Quality in Education: Supporting Disadvantaged Students and Schools, OECD, Paris, France, 2012, https://www.oecd-ilibrary.org/education/equity-and-qualityin-education_9789264130852-en.

[28] H. S. Akareem and S. S. Hossain, "Determinants of education quality: what makes students' perception different?" Open Review of Educational Research, vol. 3, no. 1, pp. 52-67, 2016.

[29] H. L. Gao, "Understanding the impact of administrative service quality on satisfaction and loyalty towards university students," Higher Education Research, vol. 5, no. 1, pp. 25-30, 2020.

[30] A. Papanthymou and M. Darra, "Assessment of the quality of electronic administrative services in a Greek higher education institution: a case study," International Journal of Higher Education, vol. 7, no. 2, p. 15, 2018.

[31] Y.-C. Chen and H.-H. Liu, "Effect of organization identity and relationship quality on teacher loyalty in teacher education departments," International Institute of Social and Economic Sciences, 2019, https://ideas.repec.org/p/sek/iacpro/8710463. html.

[32] W. R. Scull, R. Shearer, and D. Offerman, "The landscape of quality assurance in distance education," Contin High Educ Rev, vol. 75, pp. 138-149, 2011.

[33] E. Habibi, F. Najafi, G. Yadegarfar, and H. Dehghan, "The effect of mental work load on personals' sleep quality and reaction time, on the hospitals' laboratories of Isfahan," Revista Latinoamericana de Hipertensión, vol. 13, no. 3, 2018.

[34] D. Kundu, T. Mandal, M. Osta, G. Sen, H. Das, and D. Gautam, "Objective structured practical examination in 
biochemistry: an experience in Medical College, Kolkata," Journal of Natural Science, Biology and Medicine, vol. 4, no. 1, pp. 103-107, 2013.

[35] J. Westbrook, N. Durrani, D. Orr et al., "Pedagogy, curriculum, teaching practices and teacher education in developing countries. Final Report," Education Rigorous Literature Review, vol. 151, 2013.

[36] European Students' Union (ESU) (Belgium), Standards and Guidelines for Quality Assurance in the European Higher Education Area (ESG). European Students' Union. 20 Rue de la Sablonniere, 1000 Web site, European University Association, Brussels, Belgium, 2015, http://www.esu-online.org.

[37] The state of worlds' children education(unicef report), Hart2009's Blog, https://hart2009.wordpress.com/2009/10/ 24/the-state-of-worlds-children-educationunicef-report/.

[38] J. Legčević, "Quality gap of educational services in viewpoints of students," Ekonoska Misao Praksa DBK. GOD., vol. 18, no. 2, pp. 279-298, 2009.

[39] U.S. Department of Education, FACT SHEET: ED Launches Initiative for Low-Income Students to Access New Generation of Higher Education Providers, U.S. Department of Education, Washington, D.C., USA, 2020, https://www.ed.gov/news/ press-releases/fact-sheet-ed-launches-initiative-low-incomestudents-access-new-generation-higher-education-providers.

[40] N. White, L. J. Oostendorp, C. Tomlinson et al., "Online training improves medical students' ability to recognise when a person is dying: the ORaClES randomised controlled trial," Palliative Medicine, vol. 34, no. 1, pp. 134-144, 2020.

[41] N. White, L. J. Oostendorp, C. Tomlinson et al., "Online training improves medical students' ability to recognise when a person is dying: the ORaClES randomised controlled trial," Palliative Medicine, vol. 34, no. 1, pp. 134-144, 2020. 